\title{
Management of Patients with Diabetes Mellitus and Peripheral Artery Disease in the General Practice
}

\author{
George Galyfos*, Georgios Karaolanis, Fragiska Sigala and Konstantinos Filis \\ Vascular Division, First Department of Propaedeutic Surgery, University of Athens Medical School, Hippocration Hospital, Athens, Greece \\ "Corresponding author: George Galyfos MD, Ph.D, Nikis Street, Kifisia, 14561, Athens, Greece, Tel: +30-213-2086243; Fax: +30-210-7707574; E-mail: \\ georgegalyfos@hotmail.com
}

Receiving date: July 13, 2015; Accepted date: July 15, 2015; Published date: July 15, 2015

Copyright: ( 2015 Galyfos G, et al. This is an open-access article distributed under the terms of the Creative Commons Attribution License, which permits unrestricted use, distribution, and reproduction in any medium, provided the original author and source are credited.

\section{Editorial}

Peripheral artery disease (PAD) has been associated with specific risk factors such as smoking, diabetes mellitus (DM) as well as previous coronary and cerebrovascular disease [1]. The prevalence of DM for all age groups worldwide was estimated to be $2.8 \%$ (171 million) in 2000, a figure that was predicted to double over the subsequent two decades [2]. Moreover, approximately $20 \%$ to $30 \%$ of patients with diabetes also have PAD. Diabetic patients are at high risk for PAD characterized by symptoms of intermittent claudication (IC) or critical limb ischaemia. Furthermore, the presence of PAD identifies those at increased risk of ulceration, failure to heal an ulcer, and amputation [3]. Finally, patients with IC and DM have more risk cardiovascular factors, cardiovascular conditions, disability and worse haemodynamic status and quality of life than claudicant patients without diabetes [4]. Therefore, proper diagnostic and therapeutic management of such patients in the general practice is a crucial matter in order to decrease morbidity and improve quality of life.

Regarding diagnosis, inconsistencies of clinical findings in the diagnosis of PAD in diabetic patients are frequent [5]. However, detailed medical history including a systematic review of symptoms (walking impairment, claudication, ischemic rest pain, and/or nonhealing wounds) as well as careful clinical examination should be included in the initial management of such patients, especially over 50 years old with atherosclerosis risk factors [6]. According to recent Guidelines, patients at risk for PAD such as the diabetic patients should undergo comprehensive pulse examination and inspection of the feet (Class I; Level of Evidence C) [6].

The measurement of ankle-brachial index (ABI) in both extremities has also been recommended in order to verify the presence of PAD and assess additional cardiovascular risk in patients with DM (Class I; Level of Evidence B) [6]. A recent meta-analysis has shown that ABI in combination with Framingham risk score may improve the accuracy of cardiovascular risk prediction [7]. Specifically in patients with known DM, those with low $(<0.9)$ and high $(>1.4)$ ABIs are both at higher risk for cardiovascular complications $[8,9]$. Additionally, very high $(>1.4)$ as well as very low $(<0.4)$ ABI has been associated with increased mortality in diabetics [10]. However, increased arterial calcification and stiffness may limit the predictive value of $A B I$ in diabetic patients leading to a large number of falsely high measurements. However, data indicate that other tools such as the toebrachial index could overcome such limitations in patients with increased ABI $(>1.4)[6,11]$. Finally, in patients with normal resting index and symptoms of IC, ABI should be measured after exercise as well [6].

As aforementioned, patients with DM show an increased cardiovascular risk [1]. Prediabetes and DM have been independently associated with the development of subclinical myocardial damage and furthermore, with the occurrence of clinical coronary events [12]. Coronary artery disease remains the single most common cause of death in diabetics who frequently fail to perceive the classical symptoms of coronary disease [13]. Therefore, an initial evaluation including clinical examination, electrocardiogram and cardiac risk stratification is recommended even in asymptomatic patients with more than one risk factor. However, data so far does not indicate that screening with cardiac imaging reduces total cardiovascular events in asymptomatic patients. Regarding carotid artery disease, patients with DM show a very high prevalence of subclinical carotid atherosclerosis [14]. At present, carotid ultrasound is recommended in diabetic patients with cerebrovascular symptoms. However, the probability of finding a carotid stenosis $>60 \%$ is highest in diabetics with known coronary artery disease or a decreased ABI [15]. Therefore, the screening criteria could be extended in such patients. Finally, there is strong epidemiological evidence that patients with diabetes have a lower incidence as well as expansion rate of abdominal aortic aneurysm (AAA) [16], although the link between diabetes and AAA development and expansion is still unclear. A number of studies have supported the hypothesis that protection is the result of diabetesmediated changes in the vascular extracellular matrix biology, although there is the theory that treatment regimens used in diabetes may afford protection against AAA due to their pleotropic effects [17]. However, clinical suspicion - when present - should always be verified with duplex ultrasonography.

Regarding early therapeutic measures, modification of major risk factors is imperative in general practice to improve symptoms and quality of life. First of all, cessation of smoking has been associated with increase in the walking distance and reduction of overall caridovascular risk [1], and therefore, it is strongly recommended [6]. Furthermore, regulation of antidiabetic treatment and proper diet are necessary in order to reduce hemoglobin A1C to less than $7 \%$ and thus, reduce microvascular complications and potentially improve cardiovascular outcomes [1]. Finally, proper foot care, including use of appropriate footwear, daily foot inspection, skin cleansing, or use of topical moisturizing creams, should be encouraged and skin lesions/ ulcerations should be addressed urgently [1].

One of the milestones of proper management in patients with DM and PAD is regular exercise. Supervised exercise training should be performed for a minimum of 30-45 minutes, in sessions performed at least 3 times per week for a minimum of 12 weeks [1]. A recent metaanalysis showed that regardless of exercise length and modality, regularly intensive walking exercise improves walking ability in PAD patients more than usual care control, although the presence of diabetes may attenuate the improvement of walking performance in patients with PAD following exercise [18]. This could be justified as 
peripheral neuropathy, decreased muscle strength as well as obesity have been associated with walking in diabetics [19]. Regarding prediabetes stages, the American Diabetes Association (ADA) recommends that adults with prediabetes engage in $\geq 150$ minutes per week of moderate activity and target a 7\% weight loss [20]. Finally, recent studies conclude that everyday exercise programs do not only improve cardiovascular function but also improve overall mental health in diabetics [21].

Concerning proper medical therapy, a strategy of combined antihypertensive, antiplatelet and antihyperlipidemic therapy is optimal. Traditionally, the prescription of aspirin (75-325 mg daily) or clopidogrel (75 mg daily) has been associated with reduction of MI/ stroke/vascular death risk and therefore, their daily use has been recommended [1]. However, recent data have shown that a newer antiplatelet drug, namely cilostazol (100 mg twice daily), improves symptoms and increases walking distance due to its pleotropic effects (in patients without heart failure) [22]. Additionally, in patients with diabetes, a goal of less than $130 \mathrm{mmHg}$ systolic and $80 \mathrm{mmHg}$ diastolic arterial pressure should be achieved [1]. Angiotensin-converting enzyme (ACE) inhibitors as well as beta-blockers are reasonable choices to reduce the risk for adverse cardiovascular events [1]. Furthermore, statins have shown beneficial effects on several diabetic complications and predisposing risk factors such as endothelial dysfunction, oxidative stress and inflammation, metabolic syndrome, renal disease and others [23]. Low-density cholesterol levels should be lower than $100 \mathrm{mg} / \mathrm{dl}$ in patients with $\mathrm{PAD}$, and high-density cholesterol levels should remain high. When triclycerides levels are high as well, fibric acid regimens could be added [1].

In conclusion, the general practicioner plays a very important role in early diagnosis and management of a patient with DM and symptoms of PAD. Early measures could improve all-day quality of life as well as reduce overall cardiovascular risk in such patients. When there is a failure of conservative management or there is an indication for further invasive investigation or treatment, the patient should be referred to a specialist vascular surgeon immediately.

\section{References}

1. Sunderland M, De Jong M, Bates D (2013) Vascular protection in patients with diabetes admitted for vascular surgery in a canadian tertiary care hospital: pilot study. Can J Hosp Pharm 66: 227-232.

2. Wild S, Roglic G, Green A, Sicree R, King H (2004) Global prevalence of diabetes: estimates for the year 2000 and projections for 2030. Diabetes Care 27: 1047-1053.

3. Ozdemir BA, Brownrigg JR, Jones KG, Thompson MM, Hinchliffe RJ (2013) Systematic review of screening investigations for peripheral arterial disease in patients with diabetes mellitus. Surg Technol Int 23: 51-58.

4. Lozano FS, González-Porras JR, March JR, Lobos JM, Carrasco E, Ros E (2014) Diabetes mellitus and intermittent claudication: a cross-sectional study of 920 claudicants. Diabetol Metab Syndr 6: 21.

5. Jude EB, Eleftheriadou I, Tentolouris N (2010) Peripheral arterial disease in diabetes--a review. Diabet Med 27: 4-14.

6. Rooke TW, Hirsch AT, Misra S, Sidawy AN, Beckman JA, et al. (2013) Management of patients with peripheral artery disease (compilation of 2005 and 2011 ACCF/AHA Guideline Recommendations): a report of the American College of Cardiology Foundation/American Heart
Association Task Force on Practice Guidelines. J Am Coll Cardiol 61: 1555-1570.

7. Ankle Brachial Index Collaboration, Fowkes FG, Murray GD, Butcher I, Heald CL, et al. (2008) Ankle brachial index combined with Framingham Risk Score to predict cardiovascular events and mortality: a metaanalysis. JAMA 300: 197-208.

8. Hyun S, Forbang NI, Allison MA, Denenberg JO, Criqui MH, et al. (2014) Ankle-brachial index, toe-brachial index, and cardiovascular mortality in persons with and without diabetes mellitus. J Vasc Surg 60: 390-395.

9. Potier L, Roussel R, Labreuche J, Marre M, Cacoub P, et al. REACH Investigators (2015) Interaction between diabetes and a high anklebrachial index on mortality risk. Eur J Prev Cardiol 22: 615-621.

10. Wang Y, Mou Q, Zhao D, Xu Y, Hu D, et al. (2012) Predictive value of ankle-brachial index and blood glucose on the outcomes of six-year allcause mortality and cardiovascular mortality in a Chinese population of type 2 diabetes patients. Int Angiol 31: 586-594.

11. Stoekenbroek RM, Ubbink DT, Reekers JA, Koelemay MJ (2015) Hide and seek: does the toe-brachial index allow for earlier recognition of peripheral arterial disease in diabetic patients? Eur J Vasc Endovasc Surg 49: 192-198.

12. Selvin E, Lazo M, Chen Y, Shen L, Rubin J, et al. (2014) Diabetes mellitus, prediabetes, and incidence of subclinical myocardial damage. Circulation 130: 1374-1382.

13. Bravo PE, Psaty BM, Di Carli MF, Branch KR (2015) Identification of coronary heart disease in asymptomatic individuals with diabetes mellitus: to screen or not to screen. Colomb Med (Cali) 46: 41-46.

14. Van den Oord SC, Akkus Z, Renaud G, Bosch JG, van der Steen AF, et al. (2014) Assessment of carotid atherosclerosis, intraplaque neovascularization, and plaque ulceration using quantitative contrastenhanced ultrasound in asymptomatic patients with diabetes mellitus. Eur Heart J Cardiovasc Imaging 15: 1213-1218.

15. Lacroix P, Aboyans V, Criqui MH, Bertin F, Bouhamed T, et al. (2006) Type-2 diabetes and carotid stenosis: a proposal for a screening strategy in asymptomatic patients. Vasc Med 11: 93-99.

16. De Rango P, Farchioni L, Fiorucci B, Lenti M (2014) Diabetes and abdominal aortic aneurysms. Eur J Vasc Endovasc Surg 47: 243-261.

17. Torsney E, Pirianov G, Cockerill GW (2013) Diabetes as a negative risk factor for abdominal aortic aneurysm - does the disease aetiology or the treatment provide the mechanism of protection? Curr Vasc Pharmacol 11: 293-298.

18. Lyu X, Li S, Peng S, Cai H, Liu G, et al. (2015) Intensive Walking Exercise for Lower Extremity Peripheral Arterial Disease: a Systematic Review and Meta-analysis. J Diabetes.

19. Van Sloten TT, Savelberg HH, Duimel-Peeters IG, Meijer K, Henry RM, et al. (2011) Peripheral neuropathy, decreased muscle strength and obesity are strongly associated with walking in persons with type 2 diabetes without manifest mobility limitations. Diabetes Res Clin Pract 91: 32-39.

20. Rynders CA, Weltman A (2014) High-intensity exercise training for the prevention of type 2 diabetes mellitus. Phys Sportsmed 42: 7-14.

21. Sardar MA, Boghrabadi V, Sohrabi M, Aminzadeh R, Jalalian M (2014) The effects of aerobic exercise training on psychosocial aspects of men with type 2 diabetes mellitus. Glob J Health Sci 6: 196-202.

22. Bedenis R, Stewart M, Cleanthis M, Robless P, Mikhailidis DP, et al. (2014) Cilostazol for intermittent claudication. Cochrane Database Syst Rev 10: CD003748.

23. Katsiki N, Athyros VG, Karagiannis A, Mikhailidis DP (2014) The role of statins in the treatment of type 2 diabetes mellitus: an update. Curr Pharm Des 20: 3665-3674. 